\title{
Epileptiform Activity in Neurocritical Care Patients
}

\author{
Andreas H. Kramer, Nathalie Jette, Neelan Pillay, Paolo Federico, \\ David A. Zygun
}

\begin{abstract}
Background: Non-convulsive seizures have been reported to be common in neurocritical care patients. Many jurisdictions do not have sufficient resources to enable routine continuous electroencephalography (cEEG) and instead use primarily intermittent EEG, for which the diagnostic yield remains uncertain. Determining risk factors for epileptiform activity and seizures could help identify patients who might particularly benefit from EEG monitoring. Methods: We performed a cohort study involving neurocritical care patients with admission Glascow Coma Scale (GCS) scores $\leq 12$, who underwent $\geq 1$ EEG. EEGs were reviewed for presence of interictal discharges, periodic epileptiform discharges (PEDs), and seizures. Multivariate analysis was used to identify predictors of these findings and to describe their prognostic implications. Results: 393 patients met inclusion criteria. 34 underwent cEEG, usually because epileptiform activity was first detected on a routine EEG. The prevalence of PEDs or electrographic seizures was $13 \%$, and was highest with anoxic encephalopathy and central nervous system infections. Other independent predictors for epileptiform activity included a history of convulsive seizure(s), increasing age, deeper coma, and female gender. Although patients with epileptiform activity had higher mortality, this association disappeared after adjustment for confounders. Conclusion: Approximately 7-8 neurocritical care patients must undergo intermittent EEG monitoring in order to diagnose one with PEDs or seizures. The predictors we identified could potentially help guide use of resources. Repeated intermittent studies, or cEEG, should be considered in patients with multiple risk factors, or when interictal discharges are identified on an initial EEG. It remains unclear whether aggressive prevention and treatment of electrographic seizures improves neurologic outcomes.
\end{abstract}

RÉSUMÉ: Activité épileptiforme chez les patients hospitalisés à l'unité de soins intensifs neurologiques. Contexte : Selon la littérature, les crises non convulsives seraient fréquentes chez les patients hospitalisés aux soins intensifs neurologiques. Dans plusieurs endroits, les ressources ne sont pas suffisantes pour pouvoir avoir recours à l'enregistrement EEG continu (EEGc) et l'enregistrement EEG intermittent, dont on ne connaît pas le rendement diagnostique, est utilisé. La détermination des facteurs de risque de l'activité épileptiforme et des crises pourrait aider à identifier les patients susceptibles de bénéficier davantage d'une surveillance EEG. Méthode : Nous avons procédé à une étude de cohorte de patients hospitalisés à l'unité de soins intensifs neurologiques dont le score au GCS était $\leq 12$ et qui ont subi plus d'un enregistrement EEG. Les enregistrements ont été révisés pour détecter la présence de décharges interictales, de décharges épileptiformes périodiques (DEP) et de crises d'épilepsie. L'analyse multivariée a été utilisée pour identifier les facteurs permettant de les prédire et pour décrire leur influence sur le pronostic. Résultats : Trois cent quatre-vingt-treize patients respectaient les critères d'inclusion. Trente-quatre ont subi un EEGc, habituellement parce qu'une activité épileptiforme avait été détectée lors d'un EEG de routine. La prévalence des DEP ou des crises détectées à l'électroencéphalographie était de 13\%, la prévalence la plus élevée étant chez les patients atteints d'encéphalopathie anoxique et d'infection du SNC. Certains autres facteurs de prédiction d'une activité épileptiforme ont été identifiés : une histoire antérieure de crises convulsives, un âge plus avancé, un coma plus profond et le sexe féminin. Bien que les patients présentant une activité épileptiforme avaient une mortalité plus élevée, cette association n'était plus présente après ajustement en fonction de facteurs confondants potentiels. Conclusion : Environ 7 ou 8 patients hospitalisés à l'unité de soins intensifs neurologiques doivent subir une surveillance électroencéphalographique intermittente pour identifier un patient atteint DEP ou d'épilepsie. Les facteurs de prédiction que nous avons identifiés pourraient servir de guide pour une utilisation plus efficace des ressources. Des études intermittentes répétées ou l'enregistrement EEGc devraient être considérés chez les patients qui ont de multiples facteurs de risque ou quand des décharges interictales sont identifiées sur l'enregistrement EEG initial. Reste à savoir si une prévention agressive et un traitement des crises électroencéphalographiques améliore l'issue neurologique chez ces patients.

Can J Neurol Sci. 2012; 39: 328-337

A key paradigm in the care of critically ill, brain-injured patients is the avoidance of systemic and neurologic complications that may aggravate cerebral damage ${ }^{1}$. One potential cause of "secondary" brain injury is the development of seizures. Clinically apparent, convulsive seizures most often occur during the first several hours after an acute insult, and become less common thereafter ${ }^{2-6}$. However, studies using continuous electroencephalography (cEEG) have reported that a substantial proportion of patients also develop non-convulsive seizures $^{7-13}$.

Continuous electroencephalography monitoring in the intensive care unit (ICU) is labour-intensive. Most jurisdictions do not have sufficient resources to routinely use it in all neurocritical care patients. Many centers perform predominantly

From the Department of Critical Care Medicine (AHK, DAZ), Department of Clinical Neurosciences (AHK, NJ, NP, PF, DAZ), Hotchkiss Brain Institute (AHK, NJ, NP, PF, DAZ), Department of Community Health Sciences (NJ, DAZ), University of Calgary, Calgary, Alberta, Canada.

Received October 17, 2011. Final Revisions Submitted December 13, 2011 Correspondence to: Andreas H. Kramer, Departments of Critical Care Medicine \& Clinical Neurosciences, Foothills Medical Center, Hotchkiss Brain Institute, University of Calgary, Calgary, Alberta, Canada.

Email: Andreas.Kramer@AlbertaHealth Services.ca 
intermittent EEG when the possibility of non-convulsive seizures is considered. The diagnostic yield of this approach is not well studied. Determination of risk factors for epileptiform activity, especially non-convulsive seizures, would guide clinicians in using EEG resources more efficiently and could potentially assist in selecting high risk patients for cEEG.

We performed a cohort study involving consecutive stuporous or comatose [Glasgow Coma Scale (GCS) score $\leq 12$ ] neurocritical care patients admitted to ICUs within a geographic health region over 46 months. The goal was to determine the prevalence of epileptiform discharges and electrographic seizures, to identify risk factors for these findings, and to assess their prognostic implications.

\section{Materials ANd Methods}

This study was approved by the local Research Ethics Board.

\section{Study Population}

Using a prospectively maintained database, we identified consecutive patients admitted to all four regional adult ICUs between January, 2007 and October, 2010. Patients with the following conditions were included: traumatic brain injury (TBI), subarachnoid hemorrhage (SAH), intracerebral hemorrhage $(\mathrm{ICH})$, ischemic stroke, post-cardiac arrest anoxic encephalopathy, and central nervous system (CNS) infections. Diagnoses were prospectively assigned by intensivists using the ICNARC system ${ }^{14}$. The only corresponding patients in our health region who were not encompassed by this strategy were those admitted to the coronary care unit of one hospital following resuscitation from cardiac arrests, usually in the context of an acute coronary syndrome.

The rationale for excluding patients with GCS scores $>12$ was that non-convulsive seizures are less commonly sought among patients without an overtly altered level of consciousness. A GCS score $\leq 12$ is also frequently used as a threshold in categorizing patients as having a greater severity of injury ${ }^{15-17}$. The purpose of EEG in neurocritical care is usually to rule out non-convulsive seizures when consciousness remains impaired over time. Thus, we also excluded patients with a brief ICU length of stay ( $<48$ hours). Most of these patients have either catastrophic brain injury or regain consciousness quickly. Thus, we anticipated that relatively few of these patients would have had EEGs performed and it is less likely that seizures would have had a major impact on their outcome.

\section{Baseline Characteristics}

The following variables were recorded prospectively at ICU admission: age, gender, diagnosis, APACHE II and SOFA scores ${ }^{18,19}$. Attending intensivists were responsible for recording the admission GCS score. Variables that were recorded retrospectively included use of prophylactic anti-epileptic drugs (AEDs) and a history of convulsive seizures prior to performance of an EEG. We also determined whether intravenous sedatives (benzodiazepines, propofol or barbiturates) were used during, or in the 30 minutes preceding an EEG. The last computed tomogram (CT) scan performed prior to the first EEG was reviewed for the presence of focal abnormalities, ICH and cortical pathology.

\section{Outcome Variables}

Outcome variables included mortality, length of stay and maximum SOFA score. We used administrative data to determine hospital discharge disposition for each patient; for our analysis, we considered discharge home to represent a favourable outcome. Early neuro-rehabilitation is generally provided at one of the three hospitals in our region, rather than at specific rehabilitation facilities. Patients undergoing prolonged rehabilitation were only categorized as having a favourable outcome if they were ultimately discharged home. Information concerning long-term functional or neurocognitive outcomes was not available.

\section{Electroencephalography}

Reports from patients who underwent $\geq 1$ EEG were reviewed. The EEGs were interpreted by eight fellowshiptrained, provincially-certified electro-encephalographers, and prospectively categorized using the Modified Mayo Clinic system $^{20}$. Each individual interpreted EEGs at all three hospitals, using a rotating system. The presence of any interictal epileptiform discharges (spikes, sharp waves, polyspikes, spikewave), periodic epileptiform discharges (PEDs) or electrographic seizures were recorded. Periodic epileptiform discharges were further subdivided as being generalized (GPEDs), lateralized (PLEDs), bilaterally-independent (BiPLEDs) or stimulus-induced (SIRPIDs) ${ }^{21}$. Status epilepticus was considered to be present if electrographic seizures were observed continuously over more than ten minutes or there were recurrent seizures without recovery of consciousness in between $^{22}$.

\section{Management of Epileptiform Activity}

The local protocol for management of severe TBI recommends use of phenytoin for one week $^{23}$. The recommended dose is a $15-20 \mathrm{mg}$ per $\mathrm{kg}$ load, followed by $5 \mathrm{mg}$ per $\mathrm{kg}$ per day in divided doses, with subsequent adjustments based on measured levels. For other diagnoses, use of seizure prophylaxis is at the discretion of responsible physicians, although it is discouraged based on recently published guidelines ${ }^{24,25}$. Anti-epileptic drugs are never used for sporadic epileptiform discharges, unless these are especially frequent. Patients with PEDs usually receive an AED, since they are known to be at very high risk of developing seizures ${ }^{26,27}$. It is generally difficult to determine the degree to which electrographic seizures contribute to patients' depressed level of consciousness until these have been successfully treated. Thus, electrographic seizures are usually treated aggressively with short-acting intravenous sedatives (benzodiazepines or propofol). An AED (usually phenytoin) is then administered before intravenous sedation is weaned. If a second or alternative $\mathrm{AED}$ is required, leviteracetam is the most common choice.

\section{Statistical Analysis}

Continuous data were presented using median values with interquartile range (IQR). Between-group comparisons were performed using the Student's t-test or Wilcoxon rank sum test, depending on the data distribution. Categorical variables were assessed with Chi-square analysis or Fisher's exact test, as 
appropriate. Associations were expressed as odds ratios (OR) with $95 \%$ confidence intervals. P-values $<0.05$ were considered statistically significant.

Associations between potential risk factors and subsequent epileptiform activity were explored using multivariate analysis. We chose a priori to include as possible predictors basic demographic information (age, gender, and diagnosis), variables known to influence prognosis (GCS and APACHE II scores) and other factors that might be expected to influence the presence of epileptiform activity (use of sedatives and AEDs). These variables were incorporated into stepwise, backwards elimination, logistic regression models. The least significant variables were removed one by one if $p>0.10$. There is no validated method for categorizing $\mathrm{CT}$ scans across different types of brain injury: almost all patients with certain diagnoses (e.g. TBI) have abnormal CT scans while this may not be the case with other conditions (e.g. anoxic brain injury or CNS infection). Thus, we determined a priori to adjust for diagnostic category, but not radiographic information in the multivariate analysis (these two variables are closely correlated).

In assessing the relationship between epileptiform activity and outcomes, we determined a priori to adjust for age and baseline GCS score, since these factors are known to be robust predictors of outcome following neurologic injury ${ }^{17,28-31}$. We also adjusted for the degree of physiologic instability using APACHE II scores. Since age and GCS are components of the APACHE II system, we used a modified score, from which their impact was subtracted. We again also adjusted for diagnostic category (anoxic vs. other; the mortality of anoxic encephalopathy is particularly high in many studies).

To assess inter-observer variability, we randomly selected 45 EEGs for re-interpretation by three epileptologists and calculated kappa scores for agreement in the diagnosis of interictal epileptiform discharges, PEDs and electrographic seizures

\section{Results}

\section{Description of Cohort (Figure 1 \& Table 1)}

Of 1321 consecutive patients, 732 met inclusion criteria and 393 underwent at least one EEG. Of these, $58 \%$ received a single EEG; $33 \%$ had $\geq 2$ intermittent EEGs; and 9\% underwent cEEG monitoring (all but four of these had a preceding routine EEG).

Characteristics of patients are shown in Table 1. Patients undergoing EEGs had more severely impaired consciousness and higher APACHE II and SOFA scores. They also had higher ICU and hospital mortality, as well as a longer ICU length of stay. Patients with CNS infections and anoxic encephalopathy were especially likely to have had EEGs performed.

In almost all cases, EEGs were requested for the purpose of excluding subtle or non-convulsive seizures. Of the 393 patients having EEGs, 232 (59\%) were receiving AEDs at the time of assessment; this varied from $37 \%$ in patients with anoxic encephalopathy to $74 \%$ in patients with TBI $(\mathrm{p}<0.0001)$. Seventy patients $(18 \%)$ were described as having had definite convulsive seizures observed at some point prior to their first EEG; this varied from $9 \%$ of patients with anoxic encephalopathy to $33 \%$ of patients with CNS infections $(p=0.003)$. Indications for repeat EEGs were generally the same as for the initial test: suspicion for non-convulsive seizures remained because of either persistent coma, fluctuating level of

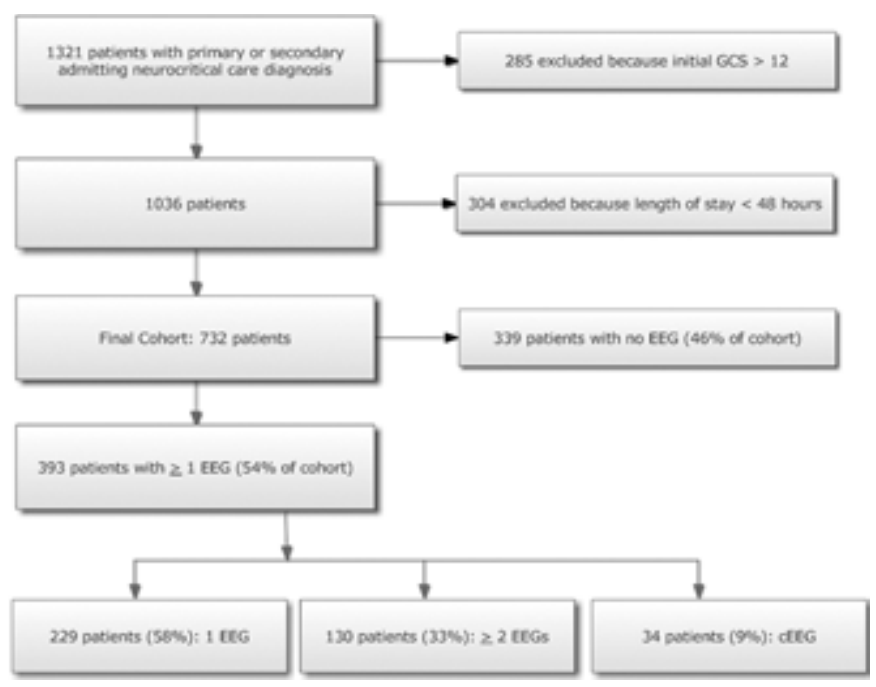

Figure 1: Flow sheet describing cohort of consecutive neurocritical care patients admitted to regional intensive care units

consciousness, abnormal movements or elevations in intracranial pressure.

The 34 patients who underwent continuous monitoring did so for a median of two days (IQR 1-4 days; range 10 hours to 65 days). The indications for cEEG were as follows: detection of electrographic seizures, PEDs or frequent epileptiform discharges on a preceding intermittent EEG (18); to guide barbiturate dosing in targeting burst-suppression (2); to rule out non-convulsive seizures in patients with persistent coma following convulsive seizures (3); to determine if abnormal movements were attributable to seizures (5); and to rule out nonconvulsive seizures in patients with fluctuating consciousness, intracranial hypertension or unexplained coma (6).

\section{Any Epileptiform Activity (Tables 2 \& 3)}

Ninety-seven patients ( $25 \%$ of those undergoing EEGs) were reported as having at least one of the following: interictal discharges, PEDs or seizures. The diagnostic category in which these findings were most common was anoxic encephalopathy. Patients with epileptiform activity were older, more often female, more likely to have had a preceding convulsive seizure and had lower GCS scores. In addition, they had higher ICU and hospital mortality, and were less likely to eventually be discharged home. Patients with or without epileptiform activity did not differ significantly in their modified APACHE II or SOFA scores, nor were AEDs associated with a lower rate of epileptiform activity.

\section{Periodic Epileptiform Discharges (Tables 2 \& 3)}

Thirty-seven patients (9\% of those undergoing EEGs) had PEDs. Of these, 16 had PLEDs, 12 had GPEDs, eight had BiPLEDs, and one had SIRPIDs. The PEDs were especially common among patients with anoxic encephalopathy and CNS infections. Patients with PEDs were older and more frequently female. They also had lower GCS values, and higher adjusted 
Table 1: Comparison of patients with and without electroencephalograms $(\mathrm{N}=732)$

\begin{tabular}{|c|c|c|c|}
\hline & EEG (393) & No EEG (339) & $P$ value \\
\hline $\begin{array}{l}\text { Diagnosis } \\
\text { Anoxic Injury } \\
\text { Ischemic Stroke } \\
\text { ICH } \\
\text { SAH } \\
\text { CNS Infection } \\
\text { TBI } \\
\end{array}$ & $\begin{array}{l}95 \\
30 \\
28 \\
29 \\
40 \\
171 \\
\end{array}$ & $\begin{array}{l}51 \\
30 \\
41 \\
38 \\
12 \\
167 \\
\end{array}$ & $<0.0001$ \\
\hline Age (years; median \& IQR) & $50(33-63)$ & $50(36-64)$ & $0.57^{*}$ \\
\hline Female Sex (percent) & $131(33 \%)$ & $112(33 \%)$ & 0.97 \\
\hline Admission GCS (median \& IQR) & $6(3-8)$ & $7(6-10)$ & $<0.0001^{*}$ \\
\hline APACHE II (median \& IQR) & $20(16-26)$ & $18(13-22)$ & $<0.0001^{*}$ \\
\hline Adjusted APACHE II (median \& IQR) ${ }^{* *}$ & $10(6-14)$ & $8(5-12)$ & $0.005^{*}$ \\
\hline First SOFA (median \& IQR) & $8(6-10)$ & $7(5-10)$ & $0.04^{*}$ \\
\hline Maximum SOFA (median \& IQR) & $11(8-13)$ & $10(7-12)$ & $<0.0001$ \\
\hline ICU Mortality & $121(31 \%)$ & $67(20 \%)$ & 0.0007 \\
\hline Hospital Mortality & $163(41 \%)$ & $90(27 \%)$ & $<0.0001$ \\
\hline $\begin{array}{l}\text { ICU LOS (days; median \& IQR) } \\
\text { Survivors } \\
\text { Non-survivors }\end{array}$ & $\begin{array}{l}11.2(6.4-16.9) \\
4.5(3.4-9.7)\end{array}$ & $\begin{array}{l}6.2(3.5-11.1) \\
3.6(2.8-5.3)\end{array}$ & $\begin{array}{l}<0.0001^{*} \\
0.0009^{*}\end{array}$ \\
\hline $\begin{array}{l}\text { Hospital LOS (days; median \& IQR) } \\
\text { Survivors } \\
\text { Non-survivors } \\
\end{array}$ & $\begin{array}{l}21.5(12.0-44.0) \\
9.0(4.0-17.0)\end{array}$ & $\begin{array}{l}24.0(12.0-52.0) \\
5.0(3.0-11.0)\end{array}$ & $\begin{array}{l}0.84^{*} \\
0.006^{*} \\
\end{array}$ \\
\hline
\end{tabular}

APACHE = Acute Physiology and Chronic Health Evaluation; CNS = central nervous system; EEG = electroencephalogram; GCS = Glasgow Coma Scale score; ICU = intensive care unit; ICH = intracerebral hemorrhage; IQR = interquartile range; $\mathrm{LOS}$ = length of stay; $\mathrm{SAH}=$ subarachnoid hemorrhage; SOFA = Sequential Organ Failure Assessment score; TBI = traumatic brain injury; * Wilcoxon rank sum test; ** This is a modified APACHE II score; the contribution of age and GCS has been removed; $\uparrow$ ICU LOS is calculated in units of hours in our database; hospital LOS is determined in units of days (thus, ICU LOS is more precise)

Table 2: Prevalence of epileptiform abnormalities, stratified by diagnoses, among neurocritical care patients undergoing electroencephalography

\begin{tabular}{l|l|l|l}
\hline & $\begin{array}{l}\text { Epileptiform } \\
\text { Discharges }\end{array}$ & $\begin{array}{l}\text { Periodic } \\
\text { Epileptiform } \\
\text { Discharges }\end{array}$ & $\begin{array}{l}\text { Electrographic } \\
\text { Seizures }\end{array}$ \\
\hline Anoxic Injury & $36 / 95(38 \%)$ & $20 / 95(21 \%)$ & $7 / 95(7 \%)$ \\
\hline Ischemic Stroke & $7 / 30(23 \%)$ & $2 / 30(7 \%)$ & $4 / 30(13 \%)$ \\
\hline ICH & $7 / 28(25 \%)$ & $2 / 28(7 \%)$ & $2 / 28(7 \%)$ \\
\hline SAH & $7 / 29(24 \%)$ & $1 / 29(3 \%)$ & $2 / 29(7 \%)$ \\
\hline CNS Infection & $11 / 40(28 \%)$ & $7 / 40(18 \%)$ & $4 / 40(10 \%)$ \\
\hline TBI & $29 / 171(17 \%)$ & $5 / 171(3 \%)$ & $8 / 171(5 \%)$ \\
\hline Total & & & $27 / 393 *(7 \%)$ \\
\hline $\begin{array}{l}\text { P (for difference in } \\
\text { prevalence among } \\
\text { various diagnoses) }\end{array}$ & $97 / 393(25 \%)$ & $37 / 393 *(10 \%)$ & 0.56 \\
\hline
\end{tabular}

CNS = central nervous system; ICH = intracerebral hemorrhage; $\mathrm{SAH}=$ subarachnoid hemorrhage; TBI

$=$ traumatic brain injury; $*$ Either PEDs or electrographic seizures occurred in 50/393 $=13 \%$ 
Table 3: Comparison of patients with and without abnormalities on electroencephalography $(\mathrm{N}=393)$

\begin{tabular}{|c|c|c|c|c|c|c|c|c|c|}
\hline & \multicolumn{3}{|c|}{ Any Epileptiform Activity* } & \multicolumn{3}{|c|}{ Periodic Epileptiform Discharges } & \multicolumn{3}{|c|}{ Electrographic Seizures } \\
\hline & Present (97) & Absent (296) & $\mathrm{P}$ & Present (37) & Absent (356) & $\mathrm{P}$ & Present (27) & Absent (366) & $\mathrm{P}$ \\
\hline Age (years, median \& IQR) & $58(45-67)$ & $48(29.5-60)$ & $<0.0001$ & $61(49-70)$ & $49.5(32-61.5)$ & 0.0009 & $55(46-69)$ & $50(33-62)$ & 0.10 \\
\hline Sex (percent female) & $45(46 \%)$ & $86(29 \%)$ & 0.002 & $18(49 \%)$ & $113(32 \%)$ & 0.04 & $15(56 \%)$ & $116(32 \%)$ & 0.01 \\
\hline $\mathrm{AED}$ & $60(62 \%)$ & $172(58 \%)$ & 0.51 & $22(59 \%)$ & $210(59 \%)$ & 0.96 & $17(63 \%)$ & $215(59 \%)$ & 0.67 \\
\hline Previous Clinical Seizure & $27(28 \%)$ & $43(15 \%)$ & 0.003 & $10(27 \%)$ & $60(17 \%)$ & 0.12 & $9(33 \%)$ & $61(17 \%)$ & 0.04 \\
\hline Admission GCS (median \& IQR) & $5(3-7)$ & $6(4-8.5)$ & 0.003 & $4(3-6)$ & $6(4-8.5)$ & 0.002 & $5(3-8)$ & $6(4-8)$ & 0.25 \\
\hline Adjusted APACHE (median \& IQR) ${ }^{* * *}$ & $10.5(7-15)$ & $9(6-13)$ & 0.34 & $13(8-16)$ & $9(6-13)$ & 0.03 & $10(7-15)$ & $10(6-14)$ & 0.66 \\
\hline First SOFA (median \& IQR) & $8(6-11)$ & $8(6-10)$ & 0.23 & $9(7-12)$ & $8(6-10)$ & 0.009 & $8(6-11)$ & $8(6-10)$ & 0.20 \\
\hline Days to first EEG (median \&IQR) & $1(0-3)$ & $1(1-4)$ & 0.05 & $1(0-2)$ & $1(0-4)$ & 0.19 & $1(0-2)$ & $1(0-3)$ & 0.15 \\
\hline Sedation $^{\dagger}$ & $16(16 \%)$ & $90(30 \%)$ & 0.007 & $4(11 \%)$ & $102(29 \%)$ & 0.02 & $6(22 \%)$ & $100(27 \%)$ & 0.56 \\
\hline Focal Abnormality on CT & $45 / 93(48 \%)$ & $177 / 291(61 \%)$ & 0.03 & $11 / 36(31 \%)$ & $211 / 348(61 \%)$ & 0.0005 & $14 / 27(52 \%)$ & $208 / 357(58 \%)$ & 0.52 \\
\hline Cortical Abnormality on CT & $50 / 93(54 \%)$ & $180 / 291(62 \%)$ & 0.17 & $15 / 36(42 \%)$ & $215 / 348(62 \%)$ & 0.02 & $14 / 27(52 \%)$ & $216 / 357(61 \%)$ & 0.38 \\
\hline Intracerebral Blood on CT $\ddagger$ & $23 / 93(25 \%)$ & $121 / 291(42 \%)$ & 0.004 & $5 / 36(14 \%)$ & $139 / 348(40 \%)$ & 0.002 & $8 / 27(30 \%)$ & $136 / 357(38 \%)$ & 0.38 \\
\hline Max SOFA (median \& IQR) & $11(9-13)$ & $11(8-13)$ & 0.65 & $12(9-14)$ & $11(8-13)$ & 0.19 & $11(9-14)$ & $11(8-13)$ & 0.54 \\
\hline $\begin{array}{l}\text { Mortality } \\
\text { ICU } \\
\text { Hospital }\end{array}$ & $\begin{array}{l}39(40 \%) \\
54(56 \%)\end{array}$ & $\begin{array}{l}82(28 \%) \\
120(41 \%)\end{array}$ & $\begin{array}{l}0.02 \\
0.009\end{array}$ & $\begin{array}{l}17(46 \%) \\
21(57 \%)\end{array}$ & $\begin{array}{l}104(29 \%) \\
153(43 \%)\end{array}$ & $\begin{array}{l}0.04 \\
0.11\end{array}$ & $\begin{array}{l}11(41 \%) \\
17(63 \%)\end{array}$ & $\begin{array}{l}110(30 \%) \\
157(43 \%)\end{array}$ & $\begin{array}{l}0.25 \\
0.04\end{array}$ \\
\hline $\begin{array}{l}\text { ICU LOS } \\
\text { Survivors } \\
\text { Non-survivors }\end{array}$ & $\begin{array}{l}9.1(4.3-16.2) \\
4.4(3.4-10.3)\end{array}$ & $\begin{array}{l}12.0(6.7-17.0) \\
7.2(3.9-13.4)\end{array}$ & $\begin{array}{l}0.14 \\
0.03\end{array}$ & $\begin{array}{l}6.8(4.6-16.0) \\
4.3(2.9-9.7)\end{array}$ & $\begin{array}{l}11.8(6.5-17.0) \\
7.0(3.8-12.7)\end{array}$ & $\begin{array}{l}0.16 \\
0.19\end{array}$ & $\begin{array}{l}14.5(8.8-20.5) \\
5.9(3.6-9.9)\end{array}$ & $\begin{array}{l}11.2(6.3-16.7) \\
6.3(3.8-12.2)\end{array}$ & $\begin{array}{l}0.20 \\
0.53\end{array}$ \\
\hline $\begin{array}{l}\text { Hospital LOS } \\
\text { Survivors } \\
\text { Non-survivors }\end{array}$ & $\begin{array}{l}19.0(8.0-50.0) \\
7.0(4.0-16.0)\end{array}$ & $\begin{array}{l}22.5(12.0-44.0) \\
10.0(4.0-18.5)\end{array}$ & $\begin{array}{l}0.67 \\
0.26\end{array}$ & $\begin{array}{l}27.0(15.0-46.0) \\
9.0(3.0-17.0)\end{array}$ & $\begin{array}{l}21.0(12.0-44.0) \\
9.0(4.0-16.5)\end{array}$ & $\begin{array}{l}0.59 \\
0.52\end{array}$ & $\begin{array}{l}36.0(29.0-68.0) \\
11.5(7.5-20.5)\end{array}$ & $\begin{array}{l}21.0(12.0-44.0) \\
8.0(4.0-16.0)\end{array}$ & $\begin{array}{l}0.12 \\
0.31\end{array}$ \\
\hline Discharge Home & $18(19 \%)$ & $92(31 \%)$ & 0.02 & $9(24 \%)$ & $101(28 \%)$ & 0.60 & $6(22 \%)$ & $104(28 \%)$ & 0.49 \\
\hline
\end{tabular}

$\mathrm{AED}=$ anti-epileptic drug ; APACHE = Acute Physiology and Chronic Health Evaluation; GCS = Glasgow Coma Scale score; ICU = intensive care unit; IQR = interquartile range; LOS = length of stay; SOFA = Sequential Organ Failure Assessment score; CT = computed tomogram) $*$ This includes sporadic (inter-ictal) epileptiform discharges, periodic epileptiform discharges and/or electrographic seizures; ** This is a modified APACHE II score; the contribution of age and GCS is removed; $†$ This refers to use of intravenous benzodiazepenes, propofol or barbiturates within the 30 minutes preceding or during the EEG; $¥$ There were nine patients, all with anoxic encephalopathy, who did not have a head CT scan

APACHE II and SOFA scores. The ICU mortality was higher when PEDs were present.

\section{Electrographic Seizures (Tables 2 \& 3)}

Twenty-seven patients (7\% of those undergoing EEGs) were found to have electrographic seizures. Of these, $22(81 \%)$ had either exclusively non-convulsive seizures or, at most, subtle manifestations (eye or mouth twitching). The remaining five had visible, clinical seizures during their EEG; however, three of these five patients were also observed to have non-convulsive seizures at other times.

In 20 of the 27 patients (74\%), electrographic seizures were detected with the first EEG; in the remaining seven $(26 \%)$, seizures were found only after repeated EEGs. Repeat EEGs were performed because of a fluctuating or persistently depressed level of consciousness (all seven patients), subtle movements concerning for seizures (2/7) and/or inter-ictal epileptiform discharges on the preceding EEG (5/7). The two patients who did not have interictal discharges on their initial EEG were being sedated at the time. Four of the seven patients had a history of convulsive seizure(s) prior to their first EEG.

All but one patient with electrographic seizures met our operational definition for status epilepticus ${ }^{22}$. There was no specific diagnostic category in which electrographic seizures were more common. Seizures were observed more often in women and among patients who had preceding convulsive seizures; no other definite univariate predictors could be identified. Patients with electrographic seizures had higher hospital mortality.
Of the 34 patients who underwent cEEG monitoring, 15 (44\%) were found to have electrographic seizures; however, in all of these cases, cEEG monitoring was initiated only because seizures $(12 / 15=73 \%)$ or PEDs $(3 / 15=27 \%)$ had first been detected on a routine EEG. Of 19 patients who underwent cEEG for other reasons (see above for indications), none were found to develop electrographic seizures.

\section{Multivariate Analysis: Predictors of Epileptiform Activity (Table 4; Figure 2)}

Several statistically significant predictors of epileptiform activity were identified. These included older age, female gender, lower GCS score and convulsive seizure(s). Overall, diagnostic category did not achieve statistical significance as a predictor, although patients with anoxic injury were more likely than those with TBI to have epileptiform activity.

Risk factors specifically for PEDs were the same. In this case, diagnostic category was also predictive, with PEDs being especially common among patients with CNS infections and anoxic injury. Electrographic seizures were associated with female sex and previous convulsive seizure(s). Associations with age and GCS score approached, but did not reach, statistical significance.

Given the apparent importance of female gender in predicting epileptiform activity, we performed a post hoc analysis stratifying female patients based on age, to indirectly assess the potential implications of sex hormone levels. Female patients were divided into categories of $>50$ compared with $<50$ years. 
Table 4: Multivariable analysis assessing predictors of epileptiform activity*

\begin{tabular}{|c|c|c|c|c|c|c|}
\hline & \multicolumn{2}{|c|}{ Epileptiform Discharges } & \multicolumn{2}{|c|}{ Periodic Epileptiform Discharges } & \multicolumn{2}{|l|}{ Electrographic Seizures } \\
\hline & Odds Ratio $(95 \% \mathrm{CI})$ & $\mathrm{P}$ & Odds Ratio $(95 \% \mathrm{CI})$ & $\mathrm{P}$ & Odds Ratio $(95 \% \mathrm{CI})$ & $\mathrm{P}$ \\
\hline Age (per decade) & $1.32(1.15-1.52)$ & $<0.0001$ & $1.39(1.11-1.76)$ & 0.005 & $1.19(0.95-1.48)^{\dagger}$ & 0.12 \\
\hline Sex (F vs. M) & $2.20(1.33-3.65)$ & 0.002 & $2.40(1.11-5.21)$ & 0.03 & $2.83(1.27-6.29)$ & 0.01 \\
\hline Initial GCS Score & $0.85(0.77-0.94)$ & 0.001 & $0.82(0.68-0.98)$ & 0.03 & $0.90(0.76-1.05)^{\dagger}$ & 0.17 \\
\hline Clinical Seizure & $2.71(1.49-4.94)$ & 0.001 & $2.81(1.13-7.00)$ & 0.03 & $2.68(1.13-6.32)$ & 0.02 \\
\hline AED & $1.50(0.85-2.65)^{\dagger}$ & 0.17 & $1.80(0.77-4.22)^{\dagger}$ & 0.17 & $1.02(0.42-2.48)^{\dagger}$ & 0.96 \\
\hline APACHE II (modified) & $0.99(0.94-1.04)^{\dagger}$ & 0.66 & $1.02(0.95-1.09)^{\dagger}$ & 0.61 & $1.01(0.94-1.09)^{\dagger}$ & 0.72 \\
\hline Sedation & $0.71(0.36-1.40)^{\dagger}$ & 0.32 & $0.54(0.17-1.74)^{\dagger}$ & 0.30 & $1.20(0.43-3.30)^{\dagger}$ & 0.73 \\
\hline $\begin{array}{l}\text { Diagnostic category } \\
\text { Anoxic Injury } \\
\text { CNS Infection } \\
\text { Stroke (All Categories) } \\
\text { TBI (reference) }\end{array}$ & $\begin{array}{l}3.00(1.61-5.59)^{\dagger} \\
1.37(0.56-3.33)^{\dagger} \\
0.71(0.34-1.49)^{\dagger}\end{array}$ & $\begin{array}{l}0.02 \\
0.49 \\
0.36\end{array}$ & $\begin{array}{l}4.50(1.50-13.46) \\
6.07(1.63-22.65) \\
0.86(0.22-3.38)\end{array}$ & $\begin{array}{l}0.007 \\
0.007 \\
0.83\end{array}$ & $\begin{array}{l}0.82(0.18-3.73)^{\dagger} \\
1.70(0.34-8.41)^{\dagger} \\
1.32(0.37-4.73)^{\dagger}\end{array}$ & $\begin{array}{l}0.80 \\
0.51 \\
0.67\end{array}$ \\
\hline
\end{tabular}

$\mathrm{AED}=$ anti-epileptic drug (at time of EEG); APACHE = Acute Physiology and Chronic Health Evaluation; CI = confidence intervals; CNS = central nervous system; GCS = Glasgow Coma Scale; TBI = traumatic brain injury; * Performed using a backwards elimination approach, where least significant variable removed if $\mathrm{p}>0.10$; $\dagger$ Last odds ratio before elimination from model (variable not retained in final model) $\$$ Includes ischemic stroke, intracerebral hemorrhage and subarachnoid hemorrhage

The association between female gender and epileptiform activity was found to be somewhat stronger in older women [OR 2.26 (1.24-4.11), $\mathrm{p}=0.007$ for age $>50$; OR $1.60(0.70-3.65), \mathrm{p}=0.26$ for age $<50]$. The same observation was made for electrographic seizures [OR 2.84 (1.10-7.29), $\mathrm{p}=0.03$ for age $>50$; OR 1.86 $(0.40-8.60), \mathrm{p}=0.42$ for age $<50]$.

We also performed a post hoc analysis assessing the impact of an increasing number of risk factors. Based on median values for the entire cohort, patients were dichotomized into categories of lower (3-6) vs. higher (7-12) GCS and younger ( $<50$ years) vs. older ( $>50$ years) age. One incremental point was assigned for each risk factor (witnessed convulsive seizure(s), female gender, diagnosis of anoxic encephalopathy or CNS infection, GCS $<6$ and age $>50$ years; maximum score of 5). A clear relationship was observed between an increasing number of risk factors and the prevalence of electrographic abnormalities (Figure 2). Among patients with a score of 0 or 1 , the proportion of patients with any epileptiform activity, PEDs or electrographic seizures was $10 \%,<1 \%$ and $3 \%$, respectively. In contrast, with a score of 3 to 5 , the prevalence of these findings was $44 \%, 21 \%$ and $14 \%$, respectively.

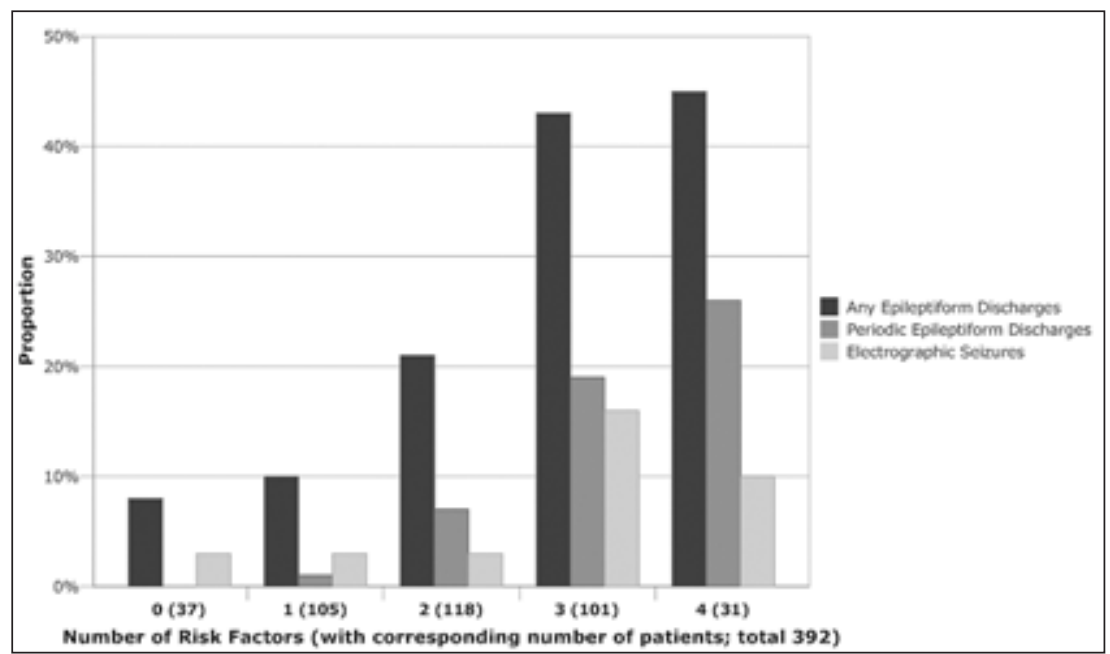

Figure 2: Relationship between increasing number of risk factors and proportion of patients with electrographic abnormalities $*+*$ Risk factors included: witnessed convulsive seizure, age $>50$, GCS < 6, female sex, diagnosis of anoxic encephalopathy or central nervous system infection (see text for details); $\dagger$ There was only one patient with all 5 risk factors. This patient had periodic epileptiform discharges, but no seizures (not shown on Figure) 
Table 5: Multivariate analysis assessing predictors of outcome*

\begin{tabular}{l|l|l|l|l}
\hline & Odds Ratio - Hospital Mortality & P & Odds Ratio - Discharge Home & P \\
\hline Epileptiform Discharges $^{\dagger \dagger}$ & $1.07(0.60-1.93)$ & 0.82 & $0.85(0.44-1.65)$ & 0.63 \\
\hline Periodic Epileptiform Discharges $^{\dagger \dagger}$ & $0.58(0.24-1.18)$ & 0.21 & $2.37(0.93-6.02)$ & 0.07 \\
\hline Electrographic Seizures $^{\dagger \dagger}$ & $1.49(0.55-4.03)$ & 0.43 & $1.10(0.37-3.32)$ & 0.86 \\
\hline
\end{tabular}

* Performed by adjusting for age, GCS, APACHE II score, and diagnostic category (anoxic encephalopathy vs. other); $\uparrow$ Age, GCS and modified APACHE II score were all significant predictors of death $(\mathrm{p}<0.001$ for each). Diagnostic category was not statistically significant for any of the models; $\$$ Age and GCS were significant predictors for discharge home $(\mathrm{p}<0.001$ for each). Modified APACHE II score approached, but did not reach statistical significance $(\mathrm{p}=0.05-0.06)$. Diagnostic category was not statistically significant for any of the models

\section{Prognostic Implications of Epileptiform Activity (Table 5)}

After adjusting for age, GCS, modified APACHE II score and diagnostic category, there was no association between epileptiform activity and subsequent mortality or discharge disposition. When we modified our definition of favourable recovery to also include transfer to another acute care facility (to account for occasional patients transferred to other rehabilitation facilities), there was still no association. In contrast, age, GCS and modified APACHE II score were all strongly predictive of death $(\mathrm{p}<0.0001$ for each model). Younger age and higher GCS were associated with a greater chance of being discharged home ( $p<0.001$ for each model).

\section{Inter-observer Agreement}

Of 45 random EEGs that were re-interpreted, there was disagreement concerning the presence of (any) epileptiform activity in only one case $(\kappa=0.94,0.84-1.00)$. There were two patients in whom epileptiform discharges were reported as being "frequent" by both interpreters, but only characterized as being "periodic" by one of them ( $\kappa$ for PEDs $=0.78,0.48-1.00$ ). Agreement concerning the presence of electrographic seizures was perfect $(\kappa=1.00)$.

\section{DISCUSSION}

In this large, multi-ICU cohort study, we found epileptiform activity to be present in a quarter of neurocritical care patients in whom at least one EEG was performed. Either PEDs or electrographic seizures were detected in $13 \%$ of those having an EEG (Table 2). If these proportions are generalizable, one would have to perform $\geq 1$ EEG in seven to eight patients to detect one with PEDs or seizures. Our study is strengthened by the fact that it was performed in a population of consecutive patients within a defined geographic region. A large proportion of patients (> $50 \%$ ) underwent $\geq 1$ EEG. However, because some patients were clearly selected for EEGs on the basis of an increased pre-test suspicion of ictal activity, it is likely that the prevalence of epileptiform abnormalities would have been less if the entire cohort had received $\geq 1$ EEG.

The prevalence of electrographic seizures (7\% of those having an EEG and $4 \%$ overall) was somewhat lower than what has been reported in other, non-population-based studies utilizing $\mathrm{cEEG}^{7-13}$. The most obvious explanation is that intermittent EEG, typically lasting about 30 minutes, is sometimes insufficient to detect non-convulsive seizures. Although many patients in our cohort $(33 \%)$ underwent more than one EEG, a relatively small proportion had cEEG monitoring (9\%), in most cases only because epileptiform activity had first been demonstrated on a routine EEG. It has been suggested that only $50-60 \%$ of patients who eventually develop electrographic seizures can be identified within the first 60 minutes $^{13}$. Interestingly, the proportion of patients found to have at least some sporadic epileptiform discharges was quite comparable to the rates of non-convulsive seizures reported by others using cEEG $(15-35 \%)^{7-13}$. It is conceivable that if these patients had been monitored for longer, a larger proportion might have eventually developed electrographic seizures. Consistent with this notion, $26 \%$ of patients who were ultimately diagnosed with electrographic seizures did not have seizures visible on their first EEG. Based on our data, clinicians should consider repeated or continuous EEG in patients with a history of witnessed seizures, when interictal discharges are seen on an intermittent EEG, or in whom the initial EEG was confounded by the need for uninterrupted sedation.

Not all studies have found non-convulsive seizures to be common, even when cEEG is used ${ }^{32}$. This may be partially explained by variability in diagnostic categories. For example, we found epileptiform activity to be less common among TBI patients compared with other diagnoses, especially anoxic encephalopathy and CNS infections; others have made similar

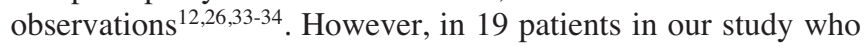
underwent cEEG monitoring without prior documentation of epileptiform activity on an intermittent EEG, not a single seizure was identified. Prospective, population-based studies enrolling well-defined categories of patients and using standardized cEEG interpretation are required to better understand the true incidence and implications of non-convulsive seizures.

Few preceding studies have been sufficiently large to perform multivariate analysis, thereby enabling identification of risk factors for epileptiform activity. We found patients with epileptiform activity to generally be older, have more severely impaired consciousness and to be more likely to have had a witnessed seizure. A previous study reported that electrographic seizures were more common in critically ill children (age < $18)^{13}$. It is possible that there may be a "U-shaped" relationship, whereby epileptiform activity is more common at extremes of 
age. Our study was performed exclusively in adult neurocritical care patients, such that this hypothesis could not be assessed. Epileptiform activity may be more common among patients with a preceding history of epilepsy ${ }^{13}$; this information was not recorded in our database. We also found epileptiform activity to be more common in females; this observation was unexpected and has not been previously reported.

The implications of critical illness on sex hormones and, in turn, the effects of hormones on neurologic recovery and seizure thresholds are complex. Emerging data demonstrates that male and female brains may respond differently to neuronal injury ${ }^{35,36}$. Estrogens have been variably reported to have both pro- and anti-convulsant properties ${ }^{37}$. Progesterone and testosterone are thought to have primarily anti-convulsant effects ${ }^{38}$. Recent animal and human studies suggest that sex hormones are neuroprotective $\mathrm{e}^{35-36,39}$, but suppressed in the setting of neurologic injury ${ }^{40}$. Preliminary randomized trials have suggested that hormone supplementation (progesterone) might improve outcomes ${ }^{41,42}$. Our post-hoc analysis revealed that the association between epileptiform activity and female gender was most pronounced among post-menopausal women. One might simplistically hypothesize that this was related to a relative deficiency of the neuroprotective effects of estrogen, progesterone and testosterone.

We did not find use of AEDs (primarily phenytoin) to be associated with a lower risk of electrographic seizures. A previous clinical trial demonstrated that prophylactic phenytoin prevents early seizures within the first week after $\mathrm{TBI}^{23}$. However, there has never been a placebo-controlled trial assessing the impact of prophylaxis on the occurrence of nonconvulsive seizures. A reduction in the incidence of seizures has not been demonstrated with diagnoses other than TBI. Considering that AEDs may have adverse effects on neurocognitive recovery, our findings seem to support recent consensus recommendations to avoid prophylaxis in patients with $\mathrm{ICH}$ or $\mathrm{SAH}^{24,25}$.

Given the limited resources available at some centers, information concerning risk factors for epileptiform activity could potentially be used to help select patients for EEGs. We identified five independent predictors. While we did not create a predictive model, there was a clear relationship between an increasing number of risk factors and a higher prevalence of epileptiform discharges and seizures. Because this was primarily a study of intermittent EEG monitoring, it remains unclear whether these same predictors could also be used to predict epileptiform activity with cEEG (the true "gold standard"). Therefore, these variables should ideally be confirmed in prospective studies using cEEG before being used to make clinical decisions. Nevertheless, an increasing number of risk factors could be considered justification to at least obtain an intermittent EEG (Figure 2). For patients with three to five risk factors, the number needing to undergo intermittent EEG monitoring in order to identify one with either PEDs or electrographic seizures was less than four (prevalence of 27\%). Future studies should also evaluate the degree to which interictal discharges on a routine EEG can predict subsequent electrographic seizures using cEEG. It is unknown how often patients develop electrographic seizures without having any preceding interictal discharges.
We found patients with epileptiform activity to have higher mortality and to be less likely to be discharged home. However, after adjusting for well-established prognostic factors (age, GCS, APACHE II) and diagnostic category, these associations were no longer statistically significant. This implies that, to some degree, the presence of epileptiform activity may be a marker for a greater severity of injury, rather than necessarily causing harm. On the other hand, a growing body of literature suggests that non-convulsive seizures are deleterious; for example, seizures have been associated with worsening cerebral edema ${ }^{8}$, raised intracranial pressure ${ }^{43}$, metabolic distress ${ }^{43}$, acute and chronic abnormalities on magnetic resonance imaging ${ }^{44,45}$, and elevation of biomarkers of cerebral injury ${ }^{46,47}$. Delays in recognition and treatment of non-convulsive seizures have been linked with higher mortality ${ }^{10}$.

Inter-observer agreement in EEG interpretation was very good to excellent $(\kappa=0.78-1.00)$. There was no significant difference in kappa scores based on the seniority of interpreters. This finding is consistent with another study performed by our group, where agreement was also excellent using cEEG in a seizure monitoring unit $(\kappa=0.89)^{48}$. Others have reported comparable findings with a similar standardized approach to the one used at our center ${ }^{49}$. However, it should be noted that interobserver agreement at other centers, or between centers, may be less consistent ${ }^{50}$.

The most important limitation of our study is that it involved primarily intermittent, rather than continuous EEG monitoring. However, this is consistent with the reality of daily practice in most hospitals across the world and provides important information concerning the diagnostic yield of this approach. In our jurisdiction, there exists a relative deficiency of EEG technicians. The estimated labour-related cost of a routine EEG at our center is $\approx \$ 90$ (90 minutes of total technician time at $\approx$ $\$ 35 /$ hour; interpretation fee of $\$ 36.98$ ). In contrast, the cost of 48 hours of cEEG monitoring is estimated to be $\approx \$ 450$ (average of 210 minutes of total technician time; interpretation fee of $\$ 110.94$ per 24 hours). The sensitivity of a strategy utilizing (repeated) intermittent EEGs, in relation to cEEG, is not known. A second limitation is that we did not have prospectively collected information available regarding functional outcomes in survivors (e.g. Glasgow Outcome or Modified Rankin Scale scores). Although we found no relationship with the likelihood of being discharged home, it remains possible that nonconvulsive seizures interfere with maximum neurologic recovery. Thus, our findings should not be interpreted as necessarily indicating that non-convulsive seizures are harmless. Indeed, it remains our practice to treat these aggressively.

In summary, we detected epileptiform activity in about a quarter of neurocritical care patients using primarily intermittent EEG. Although somewhat less common than in studies using cEEG, either PEDs or non-convulsive seizures were still present in $13 \%$ of patients. Epileptiform activity was predicted by older age, deeper coma, previous convulsive seizures, anoxic encephalopathy, CNS infections and female sex. Repeated intermittent or continuous EEG monitoring could be considered in patients with multiple risk factors, even if an initial EEG does not demonstrate PEDs or seizures. Outcomes were worse in patients with epileptiform activity, but we did not find evidence to imply that this association is causative. Prospective, multi- 
center studies using cEEG should be performed to better understand the incidence and prognostic implications of epileptiform activity. Large randomized trials would be necessary to determine whether identification, prevention and aggressive treatment of non-convulsive seizures modify outcomes.

\section{REFERENCES}

1. Suarez J. Outcome in neurocritical care: Advances in monitoring and treatment and effect of a specialized neurocritical care team. Crit Care Med. 2006;34:S232-8.

2. Annegers JF, Grabow JD, Groover RV, Laws ER, Elveback LR, Kurland LT. Seizures after head trauma: a population study. Neurology. 1980;30:683-9.

3. Butzkueven H, Evans AH, Pitman A, et al. Onset seizures independently predict poor outcome after subarachnoid hemorrhage. Neurology. 2000;55: 1315-20.

4. Berger AR, Lipton RB, Lesser ML, Lantos G, Portenoy RK. Early seizures following intracerebral hemorrhage. Neurology. 1988; 38:1363-5.

5. Arboix A, Garcia-Eroles L, Massons JB, Oliveres M, Comes E. Predictive factors of early seizures after acute cerebrovascular disease. Stroke. 1997;28:1590-4.

6. Zoons E, Weisfelt M, de Gans $\mathrm{J}$, et al. Seizures in adults with bacterial meningits. Neurology. 2008;70:2109-15.

7. Vespa PM, Nuwer MR, Nenov V, et al. Increased incidence and impact of nonconvulsive and convulsive seizures after traumatic brain injury as deteted by continuous electroencephalographic monitoring. J Neurosurg. 1999;91:750-60.

8. Vespa PM, O'Phelan K, Shaw M, et al. Acute seizures after intracerebral hemorrhage: a factor in progressive midline shift and outcome. Neurology. 2003;60:1441-6.

9. Claassen J, Jette N, Chum F, et al. Electrographic seizures and periodic discharges after intracerebral hemorrhage. Neurology. 2007;69:1356-65.

10. Young GB, Jordan KG, Doig GS. An assessment of nonconvulsive seizures in the intensive care unit using continuous EEG monitoring: An investigation of variables associated with mortality. Neurology. 1996;47:83-9.

11. Young GB, Doig GS. Continuous EEG monitoring in comatose intensive care patients. Neurocrit Care. 2005;2:5-10.

12. Rossetti AO, Logroscino G, Liaudet L, et al. Status epilepticus. An independent outcome predictor after cerebral anoxia. Neurology. 2007;69:255-60.

13. Claassen J, Mayer SA, Kowalski RG, Emerson RG, Hirsch LJ. Detection of elctrographic seizures with continuous EEG monitoring in critically ill patients. Neurology. 2004;62:1743-8.

14. Young JD, Goldfrad C, Rowan K. Development and testing of a hierachical method to code the reason for admission to intensive care units: the ICNARC Coding Method. Br J Aneaesth. 2001; 87:543-8

15. Maas AIR, Stocchetti N, Bullock R. Moderate and severe traumatic brain injury in adults. Lancet Neurol. 2008;7:728-41

16. Report of World Federation of Neurological Surgeons committee on a universal subarachnoid hemorrhage grading scale. J Neurosurg.1988;68:985-6.

17. Hemphill JC, Bonovich DC, Besmertis L, Manley GT, Johnston SC, Tuhrim $\mathrm{S}$. The ICH Score: A simple, reliable grading scale for intracerebral hemorrhage. Stroke. 2001;32:891-7.

18. Knaus WA, Draper EA, Wagner DP, Zimmerman JE. APACHE II: a severity of disease classification system. Crit Care Med. 1985; 13:818-29.

19. Zygun D, Berthiaume L, Laupland K, Kortbeek J, Doig C. SOFA is superior to MOD score for the determination of non-neurologic organ dysfunction in patients with severe traumatic brain injury: a cohort study. Crit Care. 2006;10:R115.

20. Anonymous. Clinical neurophysiology. In: Ahlskog JE, Aksamit AJ, Aronson AE, editors. Clinical examination in neurology. St. Louis: Mayo Foundation for Medical Education and Research. Mosby Year Book; 1991. p.354-451.
21. Hirsch LJ, Brenner RP, Drislane FW, et al. The ACNS Subcommittee on Research Terminology for Continuous EEG Monitoring: Proposed Standardized Terminology for Rhythmic and Periodic EEG Patterns Encountered in Critically Ill Patients. J Clin Neurophys. 2005;22:128-35.

22. Lowenstein DH, Bleck T, Macdonald RL. It's time to revise the definition of status epilepticus. Epilepsia. 1999;40:120-2.

23. Temkin NR, Dikmen SS, Wilensky AJ, Keihm J, Chabal S, Winn HR. A randomized, double-blind study of phenytoin for the prevention of post-traumatic seizures. N Engl J Med. 1990;323: 497-502.

24. Bederson JB, Connolly ES Jr, Batjer HH, et al. Guidelines for the management of aneurismal subarachnoid hemorrhage: a statement for healthcare professionals from a special writing group of the Stroke Council, American Heart Association. Stroke. 2009;40:994-1025.

25. Morgenstern LB, Hemphill JC 3rd, Anderson C, et al. Guidelines for the management of spontaneous intracerebral hemorrhage: a guideline for healthcare professionals from the American Heart Association/American Stroke Association. Stroke. 2010;41: 2108-29.

26. Carrera E, Claassen J, Oddo M, Emerson RG, Mayer SA, Hirsch LJ. Continuous electroencephalographic monitoring in critically ill patients with central nervous system infection. Arch Neurol. 2008;65:1612-8.

27. Brenner RP, Schaul N. Periodic EEG patterns: classification, clinical correlation and pathophysiology. J Clin Neurophysiol. 1990;7:249-67.

28. Murray GD, Bucher I, McHugh GS, et al. Multivariable prognostic analysis in traumatic brain injury: results from the IMPACT study. J Neurotrauma. 2007;24:329-37.

29. Rosengart AJ, Schultheiss KE, Tolentino J, Macdonald RL. Prognostic factors for outcome in patients with aneurismal subarachnoid hemorrhage. Stroke. 2007;38:2315-21.

30. van de Beek D, de Gans J, Spanjaard L, Weisfelt M, Reitsma JB, Vermeulen M. Clinical features and prognostic factors in adults with bacteria meningitis. N Engl J Med. 2004;351:1849-59.

31. Steiner T, Mendoza G, De Georgia M, Schellinger P, Holle R, Hacke W. Prognosis of stroke patients requiring mechanical ventilation in a neurological critical care unit. Stroke. 1997;28: 711-15.

32. Olivecrona M, Zetterlund B, Rodling-Wahlstrom M, Naredi S, Koskinen LD. Absence of electroencephalographic seizure activity in patients treated for head injury with an intracranial pressure-targeted therapy. J Neurosurg. 2009;110:300-5.

33. Alroughani R, Javidan M, Qasem A, Alotaibi N. Non-convulsive status epilepticus; the rate of occurrence in a general hospital. Seizure. 2009; 18:38-42.

34. Varelas PN, Hacein-Bey L, Hether T, Terranova B, Spanaki MV. Emergent electroencephalogram in the intensive care unit: indications and diagnostic yield. Clin EEG Neurosci. 2004;35: 173-80.

35. Vagnerova K, Koerner IP, Hurn PD. Gender and the injured brain. Anesth Analg. 2008;107:201-14.

36. Wigginton JG, Pepe PE, Idris AH. Rationale for routine and immediate administration of intravenous estrogen for all critically ill and injured patients. Crit Care Med. 2010;38:S6209.

37. Veliskova J, De Jesus G, Kaur R, Velisek L. Females, their estrogens and seizures. Epilepsia. 2010;51:141-4.

38. Frye CA. Effects and mechanisms of progestogens and androgens in ictal activity. Epilepsia. 2010;51:135-40.

39. Fraser DD, Hutchison JS. Estrogen therapy after traumatic brain injury: time for clinical trials? Crit Care Med. 2009;37:3181-2.

40. Wagner J, Dusick JR, McArthur DL, et al. Acute gonadotroph and somatotroph hormonal suppression after traumatic brain injury. J Neurotrauma. 2010;27:1007-19.

41. Wright DW, Kellermann AL, Hertzberg VS, et al. ProTECT: A randomized clinical trial of progesterone for acute traumatic brain injury. Ann Emerg Med. 2007;49:391-402. 
42. Xiao G, Wei J, Yan W, Wang W, Lu Z. Improved outcomes from the administration of progesterone for patients with acute severe traumatic brain injury: a randomized controlled trial. Crit Care. 2008; $12: 1-10$.

43. Vespa PM, Miller C, McArthur D, et al. Nonconvulsive electrographic seizures after traumatic brain injury result in a delayed, prolonged increase in intracranial pressure and metabolic crisis. Crit Care Med. 2007;35:2830-6.

44. Szabo K, Poepel A, Pohlmann-Eden B, et al. Diffusion-weighted and perfusion MRI demonstrates parenchymal changes in complex partial status epilepticus. Brain. 2005;128:1369-76.

45. Vespa PM, McArthur DL, Xu Y, et al. Nonconvulsive seizures after traumatic brain injury are associated with hippocampal atrophy. Neurology. 2010;75:792-8.

46. DeGiorgio CM, Heck CN, Rabinowicz AL, Gott PS, Smith T, Correale J. Serum neuron-specific enolase in the major subtypes of status epiletpicus. Neurology. 1999;52:746-9.
47. Correale J, Rabinowicz AL, Heck CN, Smith TD, Loskota WJ, DeGiorgio CM. Status epilepticus increases CSF levels of neuron-specific enolase and alters the blood-brain barrier. Neurology. 1998;50:1388-91.

48. Badawy RA, Pillay N, Jette N, Wiebe S, Federico P. A blinded comparison of continuous versus sampled review of video-EEG monitoring data. Clin Neurophysiol. 2011;122:1086-90.

49. Young GB, McLachlan RS, Kreeft JH, Demelo JD. An electroencephalographic classification for coma. Can J Neurol Sci. 1997; 24:320-5.

50. Ronner HE, Ponten SC, Stam CJ, Uitdehaag BM. Inter-observer variability of the EEG diagnosis of seizures in comatose patients. Seizure. 2009;18:257-63. 